\title{
A SWOT Analysis of Tomb IP Movies Under the Background of Internet Plus
}

\author{
Li Gong $^{1}$, Yongjun Huang ${ }^{1, *}$ \\ ${ }^{1}$ Chongqing Normal University, School of Communication, Chongqing, China \\ * Corresponding author
}

Keywords: Tomb Movies; IP; Internet Plus; Analytic method of SWOT

\begin{abstract}
In the "Internet plus" era, films that adapted from Intellectual Property (hereinafter referred to as IP) have swept the market. As a new force, such adaptations of tomb theme novels suddenly rise, gaining a foothold in the box-office market rapidly. By dissecting the strengths, weaknesses,opportunities and threats of these tomb IP movies according to analytic method of SWOT, this essay puts forward SO, WO, ST and WT four development strategies. And by comparing the strategies combo, the paper explores an effective way for tomb IP movies to survive, which also give a thought-provoking guide to domestic films.
\end{abstract}

\section{Introduction}

2015 marks the first year of the Internet plus era. On July 4th, the State Council of PRC issued Guidelines on Actively Promoting the Internet Plus Action(No.40 Document in 2015 of the State Council), pointing out that "In a new round of global technological revolution and industrial transformation, the integration of Internet and multi domain is exerting a strategic and overall influence on the economic and social development of other countries. Having being an irresistible trend of the times, films show a broad prospects and unlimited potential. As a cultural industry which is deeply mixed with internet, film has been driven and push to far away and inspired while also faced with structural challenges.

\section{Books and Scrolls Copied on Silk-- IP Movie = Internet + Movie}

"IP" is the abbreviation for "Intellectual Property". IP movie refers to the film that adapted from some copyrighted creative works. These works belong to literature or art forms (mostly network novels, etc.) and have a certain fan base[1]. In recent years, a tide of adapting from IP works to films has been raised up. IP movies become widely recognized by audience, not only have received extensive complements but also attracting BAT, the Internet industry three giants into film and television industry. According to the box office statistics, in 2015, IP movies took over seven out of ten among the top 10 best sellers of domestic films. While at the same time, the unstoppable growth of IP movie also accelerate the arrival of the bottleneck period. During the last summer stalls, although the IP movies were as much as before in quantity, compared with the same period, the box office performance is not satisfactory as usual. In recent years, the box office of hot youth series IP movies such as "Sweet Sixteen", "Fashion Is A Smile", "Never Gone" and so on, is only between 1.5-3.3 billion separately[2]. However, as soon as released on August 5th , the movie Time Raiders has quickly led the summer file box office with a sound data of 480 million in the first week and a total of 987 million until September 1st [3]. Undoubtedly, tomb theme IP films were pushed to another new climax after movies like "Chronicles of The Ghostly Tribe" and "Mojin: The Lost Legend" showed in 2015. Even though, the phenomenon that tomb films keep increasingly hot 
and the development of tomb films under the Internet plus environment is worthy of our thinking.

\section{Using The Compass to Estimate The Position of A Grave -- Tomb IP Film SWOT Matrix}

In the 1980s, the American management professor Heinz Verek proposed the SWOT analysis method in his book SWOT Matrix. By constructing matrix model, this method is supposed to find out the natural laws of development and corresponding coping strategies from a systematic analysis which covers four aspects including Strength, Opportunity and Threat. As an effective tool for comprehensive analysis of both internal conditions and external environment, SWOT analysis has been widely used by researchers since the 1980s when it was first proposed. By using this method, we can conduct a comprehensive, systematic and accurate analysis of the research object, in which S stands for Strength, W stands for Weakness, O represents Opportunity and T means Threat. After obtaining all the data from research, a permutation and combination will be conducted according to its importance and emergency. At the same time, a cross-over analysis will be conducted so as to put forward a series of solutions that could produce advantages, improve the disadvantages and deal with all threats, which will finally achieve the goal of providing guides for companies. The basic relationships among the elements are shown in Figure 1:

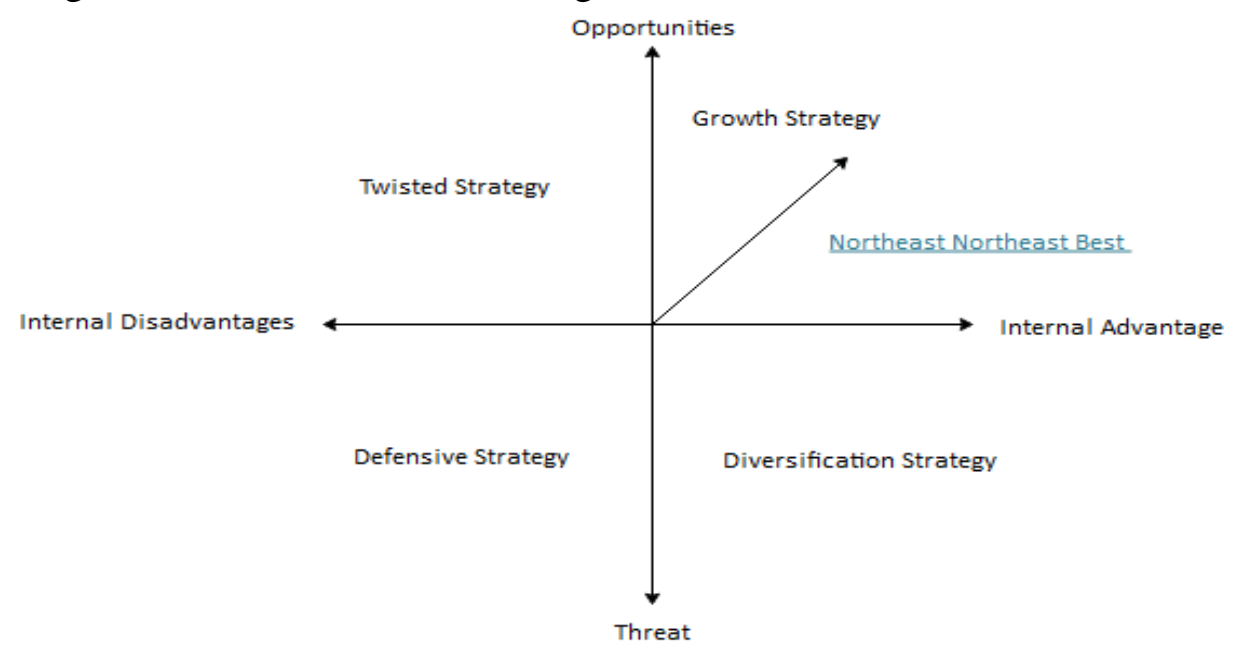

FigureI

From the above diagram we can see that the northeast stands for a kind of growth strategy that takes advantage and grasps the opportunity, hereinafter referred to as SO strategy; The northwest stands for a reverse strategy that improves the disadvantages and obtains the opportunity, hereinafter referred to as WO strategy; The southwest represents a defensive strategy that improves the disadvantages and avoids threats, hereinafter referred to as WT strategy; The southeast represents Diversification Strategy that produces advantages and overcome the threats, hereinafter referred to as ST strategy, which among above-mentioned, SO strategy is the optimal choice.

Under the background of Internet plus, which, a complex ecological background, the SWOT analysis method can clarify the development of tomb IP movies and provide practical basis for film producers and investors for their decision-making. In the current "Internet +" environment, the survival state of tomb IP movie are shown in the chart below: 


\begin{tabular}{|c|c|}
\hline Strength & Weakness \\
\hline S1: Super IP is produced by internet novels & W1: Difficult to express the original core \\
\hline S2: Excellent creative teams are rising & $\begin{array}{l}\text { W2: Lack of cultural connotation, difficult to be } \\
\text { put in good taste }\end{array}$ \\
\hline S3: Fans form the deep audience foundation & W3: Hard to produce scripts from novels \\
\hline $\begin{array}{l}\text { S4: A whole tomb IP industry chain has been } \\
\text { made }\end{array}$ & W4: Imperfect market for its derivatives \\
\hline S5: Chinese culture breeds the "Tomb culture" & $\begin{array}{l}\text { W5: Too commercial, lack of artistry and } \\
\text { humane care }\end{array}$ \\
\hline $\begin{array}{l}\text { S6: The modern elements cause the collision } \\
\text { between Chinese and Western cultures }\end{array}$ & $\begin{array}{l}\text { W6: Gimmicky in titles, a waste of attractions } \\
\text { of IP }\end{array}$ \\
\hline S7: The great potential of tomb IP movies & $\begin{array}{l}\text { W7: Entertainment-oriented and subversion of } \\
\text { values }\end{array}$ \\
\hline & W8: Boring plots and easily fatigued \\
\hline Opportunity & Threat \\
\hline $\begin{array}{l}\text { O1: Star complex significantly guides the } \\
\text { public consumption }\end{array}$ & $\begin{array}{l}\text { T1: Consumers become more rational, put } \\
\text { forward higher requirements on the quality of } \\
\text { the film }\end{array}$ \\
\hline $\begin{array}{l}\text { O2: Big data provides a rational reference for } \\
\text { the issuing marketing }\end{array}$ & $\begin{array}{l}\text { T2: It is difficult to create an atmosphere of } \\
\text { Tomb culture }\end{array}$ \\
\hline $\begin{array}{l}\text { O3: The "Film + electronic commerce" mode } \\
\text { opens road for the Tomb Raider movies. }\end{array}$ & T3: Homogenization makes works flooding \\
\hline O4: Fans economy era is approaching & $\begin{array}{l}\text { T4: Seriously uneven phenomena between } \\
\text { movie reputation and box office market }\end{array}$ \\
\hline $\begin{array}{l}\text { O5: High quality IP turns to be the most } \\
\text { popular issue of investment, crowd-funding } \\
\text { should not be underestimated. }\end{array}$ & $\begin{array}{l}\text { T5: Blindly follow the fame of IP, the film } \\
\text { industry lacks originality }\end{array}$ \\
\hline $\begin{array}{l}\text { O6: Young audience of } 20 \text { s and } 30 \text { s are the } \\
\text { main force of consumption }\end{array}$ & $\begin{array}{l}\text { T6: IP adaptation is easy to be } \\
\text { misunderstanding, facing the risk of losing the } \\
\text { cohesion of the audience }\end{array}$ \\
\hline
\end{tabular}

We set the development of tomb IP film as the highest goal, thus the basic matrix of its SWOT analysis is shown in Figure 2:

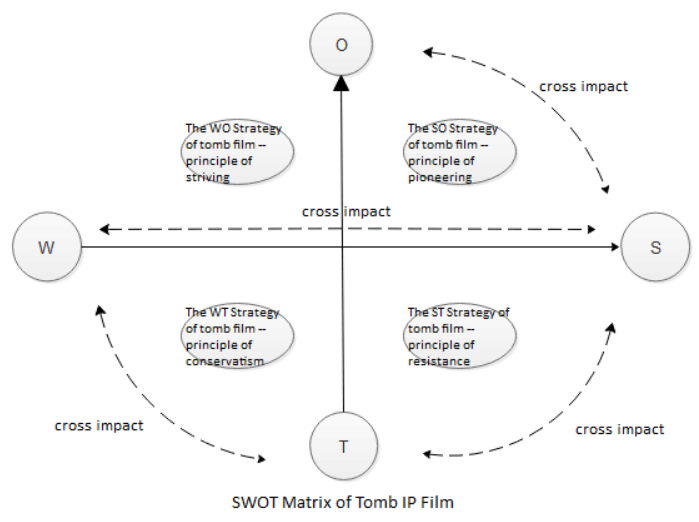

FigureII

In the basic matrix model, $\mathrm{S}$ and $\mathrm{W}$ affect each other and can achieve mutual transformation 
under certain conditions; $\mathrm{S}$ and $\mathrm{O}$ were positively correlated with each other; $\mathrm{T}$ and $\mathrm{S}$ are mutual interference type while $\mathrm{T}$ and $\mathrm{W}$ are facilitating relationship with each other; $\mathrm{O}$ and $\mathrm{T}$ are in a relationship that has no direct impact on each other. Based on the SWOT four-module relations, schemes of SO1...SOm, WO1...WOn, ST1...STi, WT1...WTJ can be proposed, and under the module logical relationship, the strategic level shows a relation like this: $\mathrm{SOm}>\mathrm{WOn}>\mathrm{STi}>\mathrm{WTj}$.

\section{Bronze Door Has Been Opened-- Strategic Reorganization of Tomb IP Film}

Through the preliminary analysis, based on the consideration of use or improve which advantages or disadvantages to seize or overcome the opportunities or threat, the author made the analysis of the development of tomb IP movies under the background of the Internet plus as follow:

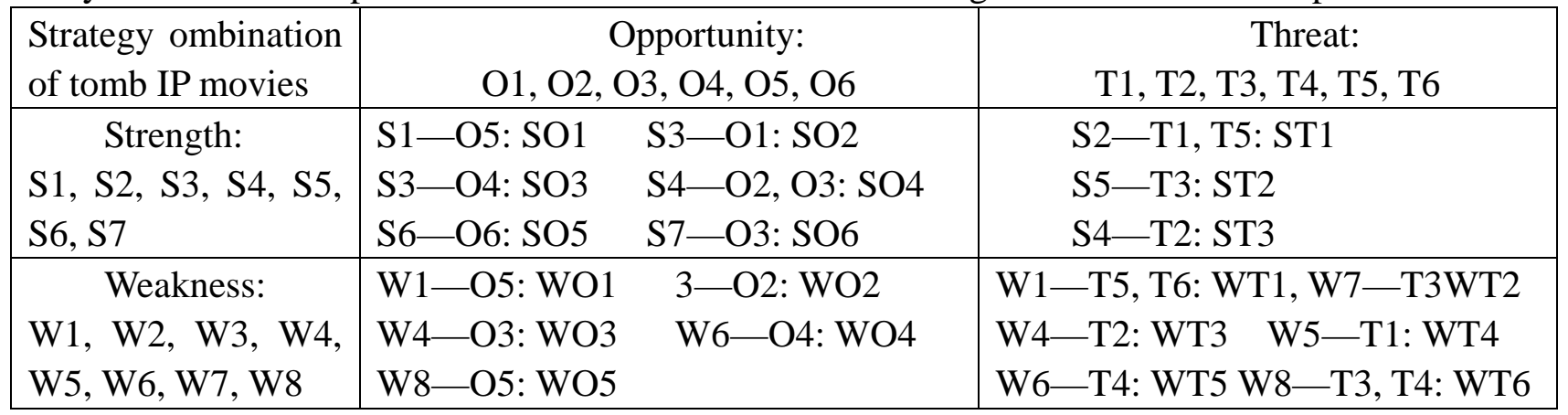

There are a total of 20 programs in the SWOT strategy combination, including six SO strategies type, five WO strategies type, three ST strategies type and six WT strategies type.

\section{Robbing Graves and Get The Treasure-- The Renewal of Tomb IP Movie Industry}

We have some existing strategies as follow:

$$
\begin{aligned}
& \text { SO1, SO2, SO3, SO4 } \\
& \text { WO3, WO4, WO5, ST1 } \\
& \text { WT3, WT4, WT5, WT6 }
\end{aligned}
$$

ST2, ST3, WT1, WT2

According to the analysis of the relational matrix of IP film SWOT: Tomb strategy level shows as SOm > WOn > STi > WTj.We set: SOm level as A, WOn level as B, STi level as C, WTj level as $\mathrm{D}$, and we let $\mathrm{A}>\mathrm{B}>\mathrm{C}>\mathrm{D}$.

If we set four schemes as a group, then we can get $\operatorname{COMBIN}(20,4)=4845$ combined modes, and we list 9 random combinations as follow: (SO1, SO2, SO3, SO4), (SO5, SO6, WO1, WO2), (WO3, WO4, WO5, ST1), (ST2, ST3, WT1, WT2), (WT3, WT4, WT5, WT6), (SO1, SO6, WO5, WT2), (SO5, WO4, WT1, WT6), (SO4, WO1, WO4, ST2), (WO2, WO5, ST3, WT3).

Then the combination level is listed as follow respectively:

$$
\begin{array}{lc}
\mathrm{SO} 1+\mathrm{SO} 2+\mathrm{SO} 3+\mathrm{SO} 4=4 \mathrm{~A} & \mathrm{SO} 5+\mathrm{SO} 6+\mathrm{WO} 1+\mathrm{WO} 2=2 \mathrm{~A}+2 \mathrm{~B} \\
\mathrm{WO} 3+\mathrm{WO} 4+\mathrm{WO} 5+\mathrm{ST} 1=3 \mathrm{~B}+\mathrm{C} & \mathrm{ST} 2+\mathrm{ST} 3+\mathrm{WT} 1+\mathrm{WT} 2=2 \mathrm{C}+2 \mathrm{D} \\
\mathrm{WT} 3+\mathrm{WT} 4+\mathrm{WT} 5+\mathrm{WT} 6=4 \mathrm{D} & \mathrm{SO} 1+\mathrm{SO} 6+\mathrm{WO} 5+\mathrm{WT} 2=2 \mathrm{~A}+\mathrm{B}+\mathrm{D} \\
\mathrm{SO} 5+\mathrm{WO} 4+\mathrm{WT} 1+\mathrm{WT} 6=\mathrm{A}+\mathrm{B}+2 \mathrm{D} & \mathrm{SO} 4+\mathrm{WO} 1+\mathrm{WO} 4+\mathrm{ST} 2=\mathrm{A}+2 \mathrm{~B}+\mathrm{C} \\
\mathrm{WO} 2+\mathrm{WO} 5+\mathrm{ST} 3+\mathrm{WT} 3=2 \mathrm{~B}+\mathrm{C}+\mathrm{D} &
\end{array}
$$

From the condition $\mathrm{A}>\mathrm{B}>\mathrm{C}>\mathrm{D}, \mathrm{SO} 1+\mathrm{SO} 2+\mathrm{SO} 3+\mathrm{SO} 4>\mathrm{SO} 5+\mathrm{SO} 6+\mathrm{WO} 1+\mathrm{WO} 2>$ $\mathrm{SO} 1+\mathrm{SO} 6+\mathrm{WO} 5+\mathrm{WT} 2>\mathrm{SO} 4+\mathrm{WO} 1+\mathrm{WO} 4+\mathrm{ST} 2>\mathrm{WO} 3+\mathrm{WO} 4+\mathrm{WO} 5+\mathrm{ST} 1>$

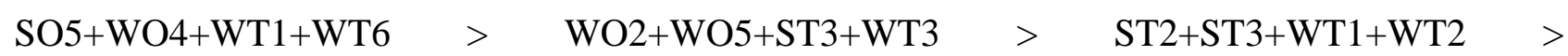
WT3+WT4+WT5+WT6.

Therefore, we arrange the combination of the level in descending order and set 
$\begin{array}{llllr}(\mathrm{SO} 1+\mathrm{SO} 2+\mathrm{SO}+\mathrm{SO} 4) & \text { as } & \text { scheme1, }(\mathrm{SO} 5+\mathrm{SO}+\mathrm{WO} 1+\mathrm{WO}) & \text { as } & \text { scheme2, } \\ (\mathrm{SO} 1+\mathrm{SO} 6+\mathrm{WO} 5+\mathrm{WT} 2) & & \text { as } & \text { scheme3, } \quad(\mathrm{SO} 4+\mathrm{WO} 1+\mathrm{WO} 4+\mathrm{ST} 2) & \text { as }\end{array}$ scheme4,(WO3+WO4+WO5+ST1) as scheme5, (SO5+WO4+WT1+WT6) as scheme6, (WO2+WO5+ST3+WT3) as scheme7, (ST2+ST3+WT1+WT2) as scheme8 and (WT3+WT4+WT5+WT6) as scheme9, then if we extract the keywords from above 9 combination schemes, we can get the following results in chart:

\begin{tabular}{|l|l|}
\hline Combination1 & $\begin{array}{l}\text { High quality super IP, consumer preferences, word of mouth marketing, the whole } \\
\text { industry chain, electronic commerce }\end{array}$ \\
\hline Combination2 & $\begin{array}{l}\text { Modern cultural elements,electronic commerce, the original core, script creation, } \\
\text { big data tools }\end{array}$ \\
\hline Combination3 & $\begin{array}{l}\text { High quality super IP, electronic commerce enrich the content, crowd-funding, } \\
\text { positive energy }\end{array}$ \\
\hline Combination4 & $\begin{array}{l}\text { The whole industry chain, electronic commerce, the original core of the story, } \\
\text { content,"The tomb culture" }\end{array}$ \\
\hline Combination5 & Derivatives of tomb IP, electronic commerce, content,crowd-funding, creative team \\
\hline Combination6 & $\begin{array}{l}\text { Modern cultural elements, the content of the story, respect for IP, positioning, } \\
\text { culture implants }\end{array}$ \\
\hline Combination7 & $\begin{array}{l}\text { Big data tools, enrich the content, crowd-funding, comprehensive penetration, } \\
\text { high-level derivatives }\end{array}$ \\
\hline Combination8 & $\begin{array}{l}\text { "The tomb culture", comprehensive penetration, respect IP, positioning, positive } \\
\text { energy }\end{array}$ \\
\hline Combination9 & High level derivatives, artistry, mining IP value, content, culture implant \\
\hline
\end{tabular}

Due to the condition of strategic position that the relationship among the combinations are: combination $1>$ combination $2>$ combination $3>$ combination $4>$ combination $5>$ combination $6>$ combination $7>$ combination $8>$ combination 9 , the more forward position it locates in, the more significant strategic effect it will have. Through the comparative analysis of keywords of combination, we can find:

IP Is The Key to Success for Tomb IP Film. In among the 9 combinations, keywords associated with IP appeared 5 times, and in "high quality super IP" appeared two times in combination 1 and combination 3 the two schemes that at a forward strategic position. Thus in the tomb IP film, the importance of IP is remarkable. Since the well-known network novel Ghost Blows the Light become the first tomb novel, Nanpai Sanshu has pushed it to the extreme with his work Time Raiders. Tomb theme quickly became a phenomenal topic. With all IP film rushing into the market in 2014, tomb theme adaption for films had quickly become beloved by audience, and Ghost Blows the Light, Time Raiders has become the super IP with mass of fans and ready-made creation system. So the IP films shared IP this strong support while adventure stories, key figures (such as Wu Xie, Zhang Qiling), tomb elements (such as tomb robbing manipulations) has constituted the condensed kernel of audience's feelings and the creation foundation of the film adaptation. But IP just opened the door to success for those filmmakers, if blindly rely on the IP will shackle the thinking of the creators. How to get further after opening the door also need creators to explore it diligently.

Electronic Commerce Is A Weapon to open The Market. In all the top five strategic combinations, has appeared the keywords of "electronic commerce". Obviously, electronic commerce has greatly changed the pattern of film marketing. Rely on the strong penetration of electronic business, movies get a more convenient, accurate and widely spread channels. Such as "online tickets purchase" has boosted the theater to upgrade their service efficiency, on the other 
hand, it expanded the influence scope of tomb film in virtually. In the "Internet plus" wave, electronic commerce has brought new opportunities for the movie's development. If tomb IP movies could seize this opportunity, with the help of electronic commerce to propaganda films based on the ticket and data flow oriented, to promote the movie and control the rhythm of the audience's interest combined with the film, to enhance the movie attendance and schedule, thus will be able to successfully open up the market.

The Content Is The Key for Tomb IP Films to Win The Reputation. Among the key words appeared in the 9 combinations, "content" has the highest frequency, and was a normal distribution. Fundamentally speaking, no matter how the times change, the core competitiveness of the tomb is still IP movie story. "Internet plus" on the one hand makes the film development more diversified, on the other hand also broaden the audience's eyes and improve their vision, thus led to an increasingly high demands on the quality of the film from audience, especially the adventure theme tomb movies. In fact, IP is a double-edged sword, if there is no good story as the foothold, it will be like movie Chronicles of The Ghostly Tribe, be argued by public. As director Daniel Lee of the movie Time Raider said:" The story is actually the soul of tomb movies."

Culture Is The Guarantee to Improve The Quality of IP Movies. The keywords of "culture” or related words have appeared in from the front combination 2 to the end combination 9, and the frequency is 6 times. Thus we are sure to say that culture occupies an indispensable position in the strategic layout of the development of IP film. The tomb In the current "Internet plus" era, under the background of big data, whether a nation could survive lies in its unique cultural characteristics and cultural connotation. The tomb films has absorbed a large number of Chinese traditional cultural elements, such as the five elements(mental, wood, water, fire and earth, held by the ancients to compose the physical universe and later used in traditional Chinese medicine to explain various physiological and pathological phenomena) and the Eight Diagrams(eight combination of three whole or broken lines formerly used in divination), constellation and Feng Shui (the location of a house or tomb), the national culture and so on. On the one hand, these ancient and mysterious traditional culture has unlimited attraction to the audience, on the other hand, bred in the fertile soil of the traditional culture birth gives the tomb culture a strong sense of cultural identity that be widely accepted by audience. In the era of knowledge economy, if people can treat tomb culture as the cradle, to timely implant some fresh culture, and knowledge elements, then the content and quality of tomb IP movies could be effectively improved.

\section{Acknowledgement}

Project Supported by Scientific and Technological Research Program of Chongqing Municipal Education Commission (Grant No. KJ1400514). Project Name: Deconstruction and Reconstruction of Cultural System Based on Chongqing's City Cultural Features-Study on the Development of Chongqing's Distinctive Culture.

\section{References}

[1]Lai Chun, Zhao Yan. The Road to Success and The Enlightenment About IP Movies in Internet Plus Era [J]. communication and copyright, 2016 (2): 84-86.

[2] China Film Association.2016 China Film Industry Research Report [R]. Beijing: China Film Press, 2016.

[3] Cbiw film, the latest statistics http://www.askci.com/news/chanye/20160901/08015358656/ 
shtml

[4] Zhang Guotao, The development of Chinese Documentary Industry Model and Ecosystem Investigation (J). Modern communication, 2014 (6):83-91.

[5] Zhang Yu. The Film Adaptation and Diversification of Industrial Development on The Theme of Time Raiders[J]. industry, 2016 (5): 148-150. 